\title{
Empirical Estimates of Okun's Law in Malta
}

\author{
Brian Micallef ${ }^{1}$ \\ ${ }^{1}$ Economics and Statistics Division, Central Bank of Malta, Castille Place, Valletta, Malta \\ Correspondence: Brian Micallef, Economics and Statistics Division, Central Bank of Malta, Castille Place, Valletta, \\ Malta.
}

Received: August 28, 2016

Accepted: October 28, 2016

Available online: November 15, 2016

doi:10.11114/aef.v4i1.1930

URL: http://dx.doi.org/10.11114/aef.v4i1.1930

\begin{abstract}
This study presents various empirical estimates of Okun's Law in Malta for the period 2000-2016. A better understanding of Okun's relationship is important for the design of macroeconomic policies as well as for forecasting purposes. In Malta, the relationship between output and unemployment is relatively weak compared to other European countries. Among the demand components, unemployment is most sensitive to private consumption and exports. The relationship is also asymmetric, with the response of unemployment to output tending to be more pronounced during recessions. Stability tests suggest that Okun's relationship is not stable, although the link has become more pronounced in recent years, while the unemployment rate consistent with full employment has been on a downward trend. Estimates from an unobserved components model suggests that Okun's Law is quite robust at cyclical frequency, with potential time-variation in the relationship being ascribed to the trend components.
\end{abstract}

Keywords: Okun's Law, asymmetry, time-variation, NAIRU, Malta.

\section{Introduction}

The double-dip recession from the financial crisis of 2009 and the sovereign debt crisis of 2012 have taken a heavy toll on the labour market in the euro area, although large differences across countries exist. This is mostly evident by divergences in unemployment rates, which have reached unprecedented levels after the crisis. This heterogeneity can be explained by a number of factors, such as differences in the source and magnitude of shocks hitting the economies, labour market institutions and the presence of pre-crisis imbalances (ECB 2012b, 2015). In addition to cyclical fluctuations, the rise in the unemployment rate was accompanied by an increase in the long-term unemployed in a number of euro area countries. This phenomenon brought back the concept of hysteresis, originally introduced in the 1980s, back to the policy and academic debate (Blanchard and Summers, 1988; Blanchard et al, 2015).

The labour market situation in Malta, the smallest member of the monetary union, is in stark contrast to that experienced in the euro area. In Malta, the unemployment rate decline to 4.9\% in 2016Q2, one of the lowest in the EU, and around 1 percentage point lower than that prevailing before the 2009 recession. The drop in unemployment was driven by robust economic activity but, perhaps surprisingly, did not lead to excessive pressure on wages, suggesting that in addition to the cyclical relationship between output and unemployment, developments in the non-accelerating inflation rate of unemployment (NAIRU) also played an important role. A significant share of the reduction in unemployment occurred from the long-term unemployment, defined as those on the unemployment register for more than one year, further suggesting potential changes in structural unemployment.

Cross-country empirical estimates usually suggest that Okun's coefficient in Malta - the negative relationship between output and unemployment - is relatively weak compared to other EU economies (ECB, 2012). This could be due, for instance, to the relatively large size of the public sector, which tends to be sheltered from cyclical fluctuations. Another explanation could be due to labour hoarding. If hiring new workers involves substantial search and training costs, firms may choose to adjust the utilization rate of labour during a period of temporary weak demand instead of firing workers. Survey evidence indeed suggests that the majority of Maltese firms prefer to cut non-labour costs and overtime rather than shedding jobs when faced with temporary shocks (Central Bank of Malta, 2012).

In addition, it is widely recognised that Okun's 'Law' is only a statistical relationship and not a structural feature of an economy. This means that this relationship may not be stable over time, especially when the economy undergoes structural changes. Malta is a prime example in this regard, with profound structural changes in the economy, especially 
after EU membership in 2004 and various reforms in recent years intended to attract and retain more people in the labour market (Micallef, 2015; Grech, 2015). Similarly for other countries, a number of studies have also suggested a breakdown in Okun's relationship in the aftermath of the Great Recession of 2009 (Knoteck, 2007; IMF, 2012).

A better understanding of Okun's Law is important for the interpretation of unemployment movements and the design of macroeconomic policies. The negative relationship between output and unemployment suggests that demand stimulus can help in reducing high unemployment. On the contrary, sceptics of this view suggest that the breakdown in Okun's relationship is due to problems in the labour market, such as skill mismatches, which implies that labour market policies, such as training and re-skilling, instead of demand stimulus, is necessary to lower unemployment (McKinsey, 2011). In addition, Okun's relationship is also a useful tool for forecasting, provided that potential time-variation is taken into consideration (Knoteck, 2007).

This study contributes to the scare literature on this topic in Malta by looking at the output-unemployment nexus from various perspectives. It presents empirical estimates for Okun's law, tests the stability of this relationship over time and its sensitivity to the economic cycle. In addition, we focus on both cyclical and well as structural changes in this relationship. The latter is obtained using an unobserved-components model in which both output and unemployment are decomposed into their respective trends and cycles.

The rest of this article is organized as follows. Section 2 looks at Okun's Law and the numerous variants found in the empirical literature. Section 3 estimates different empirical specifications of Okun's Law for Malta focusing on the period 2000-2016. It also tests the stability of the various relationships, in particular, Okun's coefficient and the rate of unemployment consistent with full employment. Section 4 describes the unobserved-component model that is used to decompose output and unemployment into their respective trends and cycle. Section 5 concludes and provides some policy recommendations based on the main findings.

\section{Okun's Law}

The original formulation of Okun's Law, estimated on US data for the period 1948Q2-1960Q4, suggests that a $2.0 \%$ to $3.0 \%$ drop in GDP growth is associated with an increase in the unemployment rate of around 1 percentage point (Okun, 1962). Since then, this relationship has been estimated for a large number of countries over different sample periods. Okun's coefficient is also found to differ considerably across countries. For instance, in a cross-country study, Ball et al (2012) report coefficients that range from -0.15 in Japan, -0.45 in the US and -0.85 in Spain. These differences are due to the characteristics of the national labour markets, such as the tradition of lifetime employment in Japan and the prevalence of temporary contracts in Spain.

Pre-crisis estimates for the euro area suggest that a 1 percentage point decline in GDP growth leads to a contemporaneous 0.4 percentage point rise in the unemployment rate (ECB, 2011). Estimates that include the 2009 recession point to a weakening in Okun's coefficient to around 0.3 as measures adopted during the crisis to limit the pace of job destruction have somewhat distorted in this relationship.

The literature distinguishes between two main versions of Okun's Law. The 'difference' version relates the change in unemployment rate to real GDP growth:

$$
\Delta \mathrm{u}_{t}=\alpha+\beta \Delta \mathrm{y}_{t}+\varepsilon_{t}
$$

where $\Delta \mathrm{u}$ represents the annual percentage point change in the unemployment rate and $\Delta \mathrm{y}$ measures the annual percentage change in real GDP. Equation (1) captures the contemporaneous relationship between the change in output and unemployment. The parameter $\beta$ refers to Okun's coefficient, which a priori is expected to be negative. The ratio $\frac{-\alpha}{\beta}$ represents the rate of output growth consistent with a stable unemployment rate.

A dynamic version of Okun's relationship is commonly applied in the empirical literature through the introduction of lags in equation (1) in both the dependent and the explanatory variables (Knotek, 2007; Ball et al, 2012; Casez and Verick, 2011):

$$
\Delta u_{t}=\alpha+\sum_{i=0}^{p} \beta_{i} y_{t-i}+\sum_{j=1}^{q} \gamma_{j} \Delta u_{t-j}+\varepsilon_{t}
$$

Equation (1a) is meant to account for changes in economic activity that affect the labour market with a lag and for the possible omission of relevant variables from the equation. In this case, Okun's coefficient from the dynamic specification is computed as:

$$
\beta=\sum_{i=0}^{p} \beta_{i} / 1-\sum_{j=1}^{q} \gamma_{j}
$$

The second version - the 'gap' model - relates the level of the unemployment rate to the output gap, i.e. the difference between actual and potential GDP: 


$$
\mathrm{u}_{t}=\alpha+\beta \tilde{\mathrm{y}}_{t}+\varepsilon_{t}
$$

where $\tilde{y}_{t}$ refers to the output gap, that is, the deviation of output from its potential. In this specification, the parameter $\alpha$ is associated with the unemployment rate that is consistent with full employment while, a priori, one expects $\beta$ to be negative. The main difficulty with equation (2) is that both the output gap and potential output are unobservable variables. These latent variables are usually estimated by statistical filtering techniques or by using a production function approach. Given the uncertainty associated with the estimates of these unobservable variables, empirical studies typically estimate equation (2) using different specification of the output gap, derived from alternative approaches.

In addition to these two specifications, a number of studies also look at different variants of Okun's Law. For instance, Ball et al. (2012) and Casez and Verick (2011) point towards the presence of asymmetries in this relationship, arguing that unemployment is likely to rise more during recessions than to decrease during periods of expansion. Common specifications of the asymmetric version are the following:

$$
\begin{gathered}
\Delta u_{t}=\alpha+\sum_{i=0}^{p} \beta_{i} \Delta y_{t-i}+\sum_{k=0}^{r} \theta_{k}\left(d^{-} . \Delta y_{t-k}\right)+\sum_{j=1}^{q} \gamma_{j} \Delta u_{t-j}+\varepsilon_{t} \\
\Delta u_{t}=\alpha+\beta^{+} \Delta y_{t}^{+}+\beta^{-} \Delta y_{t}^{-}+\sum_{j=1}^{q} \gamma_{j} \Delta u_{t-j}+\varepsilon_{t}
\end{gathered}
$$

Equation (3a) accounts for asymmetry by retaining overall GDP growth but also adding $d^{-}$, a dummy variable that takes the value of 1 in periods of negative GDP growth rates. In this way, equation (3a) tests for both the standard Okun's coefficient and the coefficient during periods of negative GDP growth.

Specification (3b) tests directly for asymmetry. In this case, the GDP growth rate is split into, and replaced by, two variables. One is $\Delta y_{t}^{-}$, which consists of the rate of change in GDP for those quarters when GDP contracted, while the remaining quarters show a value of zero. The other variable is $\Delta y_{t}^{+}$which contains the rate of change in GDP for those quarters when GDP increased, while the remaining quarters show a value of zero.

Other studies use a disaggregated approach to estimate the impact of the individual demand components on unemployment. Usually these studies reveal that unemployment dynamics differ considerably depending on which GDP component is driving growth. A common specification would be the following:

$$
\Delta \mathrm{u}_{t}=\alpha+\sum_{g} \beta_{g} \vartheta_{g} \Delta \mathrm{y}_{g, t}+\varepsilon_{t}
$$

where $\Delta \mathrm{y}_{g}$ consists of private consumption, government consumption, investment, exports and imports. $\vartheta_{g}$ refers to the average weight of each component in GDP, while $\beta_{\mathrm{g}}$ are the separate estimated coefficients for each component.

Pesliakaite (2015) finds that the unemployment rate in Lithuania is most sensitive to the growth in private consumption followed by exports. Similarly, based on a panel consisting of all euro area countries, ECB (2012) also finds that unemployment is most sensitive to developments in private consumption while foreign trade has the lowest impact. Apap and Gravino (2014) make a distinction between services and manufacturing and find that the unemployment rate in Malta is more sensitive to developments in the services sector compared to industry.

\section{Empirical Estimates of Okun's Law in Malta}

Chart 1 shows the annual changes in the unemployment rate against real GDP growth for Malta, using annual data for the period between 2001 and 2015. The chart shows that, as expected, there is a negative relationship between real GDP growth and the change in the unemployment rate, with periods of economic expansions generally associated with a declining unemployment rate and vice versa. Using annual data, Okun's coefficient is estimated at 0.14 , while the rate of output growth consistent with a stable unemployment rate stands at $2.0 \%$. This means that a 1 percentage point increase in GDP growth in excess of $2.0 \%$ lowers the unemployment rate by around 0.14 percentage point. 


\section{Okun's Law in Malta}



Figure 1. Okun's Law in Malta

Excluding 2004 from the analysis, which was an outlier, the estimated Okun's coefficient increases slightly to 0.17 , while the rate of output growth consistent with a stable unemployment rate rises to $2.4 \%$. In this case, one also observe a considerable improvement in the fit of the equation, with the R2 increasing from 0.34 to 0.50 .

Table 1 presents further econometric estimates for the difference version of Okun's Law for Malta, using quarterly data from 2001Q1 until 2016Q2. Since quarterly data in Malta start in 2000, the first four observations are lost when taking the annual growth rate in GDP and the change in the unemployment rate. GDP and unemployment statistics are sourced from the National Accounts and the Labour Force Survey, respectively.

The first equation in Table 1 reports the static specification, with an Okun's coefficient of 0.10 and the rate of output growth consistent with a stable unemployment rate at $1.5 \%$. The second column presents the dynamic specification, with lags of both dependent and explanatory variables. The dynamic version suggests that the effect of contemporaneous GDP growth on unemployment is not statistically significant, suggesting that developments in domestic economic activity affect the labour market with a lag. The short-run Okun's coefficient, lagged by one quarter, is estimated around 0.06, while the long-run coefficient stands at 0.13. These estimates are broadly in line with Apap and Gravino (2014), who estimates Okun's Law in Malta using administrative data on unemployment instead of the Labour Force Survey.

Table 1. Estimates of Okun's Law in Malta: Difference Version (2001Q1-2016Q2)

\begin{tabular}{|c|c|c|c|c|c|}
\hline & \multirow{2}{*}{$\begin{array}{l}\text { Static } \\
\text { (i) }\end{array}$} & \multirow{2}{*}{$\begin{array}{c}\text { Dynamic } \\
\text { (ii) }\end{array}$} & \multicolumn{3}{|c|}{ With asymmetries } \\
\hline & & & (iii) & (iv) & (v) \\
\hline$\beta 0$ & $-0.097 * * *$ & & & & \\
\hline$\beta 1$ & & $-0.058 * *$ & -0.035 & & \\
\hline$\beta+$ & & & & & 0.012 \\
\hline$\beta-$ & & & $-0.182 *$ & $-0.226 * * *$ & $-0.239 * *$ \\
\hline$\gamma 1$ & & $0.537 * * *$ & $0.483 * * *$ & $0.510 * * *$ & $0.515 * * *$ \\
\hline$\alpha$ & 0.150 & 0.093 & -0.012 & $-0.111 *$ & -0.148 \\
\hline$-\alpha / \beta$ & 1.546 & 1.603 & & & \\
\hline $\mathrm{R} 2$ & 0.13 & 0.419 & 0.453 & 0.441 & 0.441 \\
\hline Obs & 62 & 61 & 61 & 61 & 61 \\
\hline
\end{tabular}

Notes: t-statistics in parenthesis, ${ }^{*} \mathrm{p}<0.10,{ }^{* *} \mathrm{p}<0.05,{ }^{* * *} \mathrm{p}<0.01$

An important assumption in the specifications of Okun's Law outlined above is that the response of unemployment to GDP is restricted to be the same during expansions and recessions. Asymmetry in this relationship would imply that the response of the unemployment rate to changes in GDP depends also on whether the economy is expanding or contracting.

Columns (iii) to (v) test for asymmetry using different specifications. These models suggest that Okun's relationship in Malta is asymmetric, with the response of unemployment to output tending to be more pronounced during recessions. A similar finding for Malta was reported in Casez and Verick (2011). Estimates of Okun's coefficient during periods of positive growth are much lower than those during periods of negative growth, but these estimates are not statistically 
significant and with the wrong sign. According to the estimates in Table 1, Okun's coefficient during a recessionary environment can increase to around 0.4 in the long run and hence, is significatly more pronounced than those presented in the symmetric specifications.

Table 2 presents the results for the separate components of GDP in line with the equation (4). The unweighted coefficients suggest that changes in the unemployment rate could differ depending on which aggregated demand component is driving GDP growth. The results suggest that unemployment is most sensitive to private consumption, followed by exports of goods and services. The importance of private consumption is in line with the findings reported in ECB (2012) and Pesliakaite (2015). Given their relatively small shares in GDP, changes in public consumption and investment have a low impact on unemployment. The responsiveness of unemployment to the external components is somewhat biased by the presence of special purposes entities, which inflate the shares of exports and imports in GDP. Accounting for these entities would presumably lower the elasticities of exports and imports, which leaves private consumption as the most important GDP category in influencing the unemployment rate.

Table 2. Okun's Law in Malta: Disaggregated Approach (2001Q1-2016Q2)

\begin{tabular}{lccc}
\hline & $\begin{array}{c}\text { Okun's } \\
\text { coefficient to } \\
\text { GDP } \\
\text { components }\end{array}$ & $\begin{array}{c}\text { Average } \\
\text { weight of } \\
\text { GDP } \\
\text { component }\end{array}$ & $\begin{array}{c}\text { Unemployment } \\
\text { elasticity to GDP } \\
\text { components }\end{array}$ \\
\hline Private consumption & $-0.099 * * *$ & 0.59 & -0.06 \\
Public consumption & $-0.040 * * *$ & 0.20 & -0.01 \\
Investment & $-0.007 * * *$ & 0.20 & 0.00 \\
Exports & $-0.037 *$ & 1.30 & -0.05 \\
Imports & 0.021 & 1.29 & 0.03 \\
$\alpha$ & $0.299 * *$ & & \\
\hline R2 & 0.309 & & \\
Obs & 60 & & \\
\hline
\end{tabular}

Notes: t-statistics in parenthesis, $* \mathrm{p}<0.10, * * \mathrm{p}<0.05, * * * \mathrm{p}<0.01$

Table 3 presents the estimates of the 'gap' version of Okun's Law, in line with equation (2). Estimates of the output gap are derived from a Hodrick-Prescott filter with a smoothing value of 1600. To avoid the end of sample bias inherent in this filter, estimates of GDP were extended by three years using the projections published by the European Commission in the Spring Economic Forecasts 2016. Given the uncertainty surrounding estimates of potential output, two alternative measures are used. The first estimate is derived from a Cobb-Douglas Production Function, in line with Grech and Micallef (2015). The second one is derived from a multivariate filter that blends statistical approaches with economic information, based on long-standing relationships in economic theory, such as the Phillips Curve (Micallef, 2016).

Table 3. Gap Version of Okun's Law (2001Q1-2016Q2)

\begin{tabular}{lcccc}
\hline \multicolumn{5}{c}{ Output Gap } \\
& $\lambda=1600$ & $\begin{array}{c}\lambda=1600 ; \text { 4-quarter } \\
\text { moving average }\end{array}$ & $\begin{array}{c}\text { Production function } \\
\text { (Grech \& Micallef, 2015) }\end{array}$ & $\begin{array}{c}\text { Multivariate filter } \\
\text { (Micallef, 2016) }\end{array}$ \\
\hline$\beta$ & -0.110 & $-0.171^{*}$ & $-0.235 * * *$ & $-0.276 * * *$ \\
$\alpha$ & $6.625 * * *$ & $6.614 * * *$ & $6.627 * * *$ & $6.643 * * *$ \\
\hline R2 & 0.040 & 0.049 & 0.104 & 0.194 \\
Obs & 66 & 63 & 66 & 66 \\
\hline
\end{tabular}

Notes: t-statistics in parenthesis, ${ }^{*} \mathrm{p}<0.10, * * \mathrm{p}<0.05$, $* * * \mathrm{p}<0.01$

According to the estimates, a 1 percentage point increase in the output gap lowers the unemployment rate by 0.1 to 0.3 
percentage points, while NAIRU is estimated around $6.6 \%$. The assumption of a constant NAIRU over the sample period, however, could be too restrictive since a number of studies have pointed to a downward trend in NAIRU in Malta over the past decade (Micallef, 2016, 2016a). This point is addressed in the next section, which tests for stability in both Okun's coefficient as well as NAIRU.

\subsection{Testing the Stability of Okun's Coefficient and NAIRU}

A number of studies have recently questioned the stability of Okun's coefficient over time (Knoteck, 2007; IMF, 2012). To test this hypothesis, both the 'difference' and the 'gap' versions of Okun's Law presented above are re-estimated using rolling regressions. This means that the equation is estimated over a sequence of sample periods, thereby producing a set of estimated coefficients. This exercise applies the static specification in Table 1, as well as the model in Table 3, using a fixed window of 28 quarters (seven years), which broadly constitutes the length of the business cycle. More specifically, the first equation is estimated over the period 2001Q1-2007Q4, the second one for 2001Q2-2008Q1, and so on. This process is repeated until the final regression with a 28-quarter window includes the last observation from the sample (i.e. 2009Q3 - 2016Q2).

If the relationship between output and unemployment remained stable over the sample period, the coefficients from the regressions estimated over different samples should be relatively similar. On the contrary, substantial changes in the coefficients imply that the relationship has not been stable over time. This method provides the means for detecting whether developments in the early part of the last decade are influencing the estimation of recent relationships.

Rolling estimate of Okun's coefficient

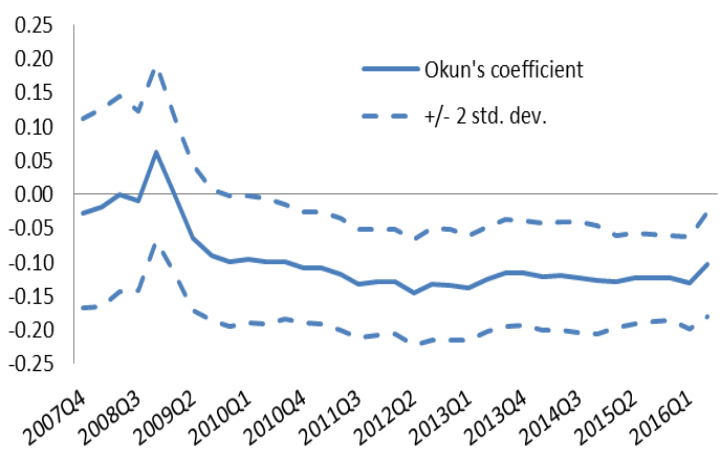

\section{Rolling estimate of NAIRU}

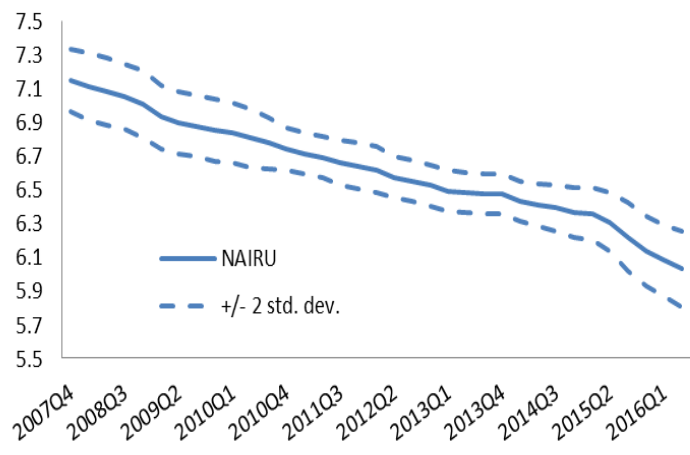

Chart 2. Rolling Estimates of Okun's Coefficient and NAIRU

Chart 2 shows substantial time-variation in both the unemployment-output relationship and NAIRU in Malta over the last decade. In particular, Okun's coefficient was not statistically significant in the early 2000s but has been relatively stable and statistically significant since 2005 , standing at slightly higher than 0.10 . Similarly, the rolling estimate of NAIRU, that is, the parameter $\alpha$ in Equation (2), has been on a downward trend, declining from above $7 \%$ in the early 2000s to below $6 \%$ in the latter part of the sample. In line with Micallef (2016), the rolling estimate of NAIRU was not affected by the Great Recession of 2009, contrary to the experience in most other EU countries.

The increased responsiveness of unemployment to economic activity since the mid-2000s can be partly explained by the increased use of part-timers and workers with temporary contracts. For example, the share of temporary employees in total employees has almost doubled over the past decade. These workers have less employment protection relative to those with permanent contracts and, hence, their contracts are less likely to be renewed in times of falling demand. The share of employees with part-time work increased from slightly less than $9 \%$ of total employment in 2004 to more than $16 \%$ a decade later.

This phenomenon should be seen in the light of structural changes that have taken place in the Maltese economy over the last decade. In particular, these are related to the diversification of the economy towards the services sector, which is more labour-intensive, both in terms of output and employment, at the expense of traditional industries (Grech, 2015). For instance, the share of employment in the manufacturing sector has steadily declined from $24.5 \%$ of total employment in 1995 to $12.0 \%$ in 2014 . At the same time, the share of services excluding wholesale, retail and tourism has gone up from $15.9 \%$ to $25.6 \%$. (Note 1) These changes in the services sector occurred primarily after EU membership in 2004. The responsiveness of unemployment to output is thus affected by these trends in the labour market, with service industries being the main driver of employment growth in recent years, in conjunction with an expansion in the supply of labour driven by a gradual increase in the participation rate of females.

The take away from this section is that, given potential changes in both the cyclical and trend components, one could 
benefit from a modelling framework that jointly models both the trend and cycle in output and unemployment.

\subsection{Okun's Law and NAIRU through the Lens of a Semi-Structural Filter}

This section develops a trend-cycle model to better understand the evolution of output and unemployment in Malta over the past 15 years. The framework builds on similar models in the literature, such as Lafourcade et al (2016) and Micallef (2016), having, at its core, the Quarterly Projection Model developed by the IMF in recent years (Carabenciov et al, 2008; Benes et al, 2010). In addition to output and unemployment, the vector of observable variables also includes foreign demand to capture the importance of foreign developments in shaping domestic activity in a small and open economy.

The structure of the model is the following:

$$
\begin{gathered}
\mathrm{y}_{\mathrm{t}}=\overline{\mathrm{y}}_{\mathrm{t}}+\tilde{\mathrm{y}}_{\mathrm{t}} \\
\overline{\mathrm{y}}_{\mathrm{t}}=\overline{\mathrm{y}}_{\mathrm{t}-1}+\mathrm{G}_{\mathrm{t}} / 4-\vartheta \Delta \overline{\mathrm{u}}_{\mathrm{t}}+\varepsilon^{\overline{\mathrm{y}}} \\
\mathrm{G}_{\mathrm{t}}=(1-\tau) \mathrm{G}_{\mathrm{t}-1}+\tau \overline{\mathrm{g}}+\varepsilon^{\mathrm{G}} \\
\tilde{\mathrm{y}}_{\mathrm{t}}=\theta_{1} \tilde{\mathrm{y}}_{\mathrm{t}-1}+\theta_{2} \tilde{y}_{t}^{\text {for }}+\varepsilon^{\widetilde{y}} \\
\mathrm{u}_{\mathrm{t}}=\overline{\mathrm{u}}_{\mathrm{t}}+\tilde{\mathrm{u}}_{\mathrm{t}} \\
\overline{\mathrm{u}}_{\mathrm{t}}=\overline{\mathrm{u}}_{\mathrm{t}-1}+\varepsilon^{\overline{\mathrm{u}}} \\
\tilde{\mathrm{u}}_{\mathrm{t}}=\alpha_{1} \tilde{\mathrm{u}}_{\mathrm{t}-1}-\alpha_{2} \tilde{\mathrm{y}}_{\mathrm{t}}+\varepsilon^{\widetilde{\mathrm{u}}} \\
\tilde{y}_{t}^{\text {for }}=\rho \tilde{y}_{t-1}^{\text {for }}+\varepsilon^{\text {yfor }}
\end{gathered}
$$

Equations (i) to (iv) describes the output block. Equation (i) is an identity, defining log-GDP (y) as the sum of two unobserved components, the trend $\left(\overline{\mathrm{y}}_{\mathrm{t}}\right)$ and the cycle $\left(\tilde{\mathrm{y}}_{\mathrm{t}}\right)$. (Note 2) In equation (ii), trend output is assumed to follow a random walk with a time-varying drift, with $\varepsilon^{\bar{y}}$ being a shock to the level of trend output. Trend output depends on the economy's underlying trend growth $\left(\mathrm{G}_{t}\right)$, as well as on changes in trend unemployment $\left(\overline{\mathrm{u}}_{t}\right)$. The latter captures the impact of changes in NAIRU on the economy's growth potential, with $\vartheta$ referring to the share of labour in GDP, as in Benes (2010). Equation (iii) describes the time-varying drift in the growth rate of trend output. In the long run, the growth rate of trend output converges to its steady state growth rate $(\overline{\mathrm{g}})$ but shocks to the growth rate of trend output $(\varepsilon \mathrm{G})$ can push it away from the steady state growth in the short to medium term. The parameter $\tau$ determines the speed with which the economy returns to its steady state growth rate after a shock. Finally, equation (iv) describes the cyclical component of output, which is assumed to depend on its own lagged value as well as on foreign demand $\left(\tilde{y}_{t}^{\text {for }}\right)$, with $\varepsilon^{\tilde{y}}$ capturing disturbances to cyclical output.

Equations (v) to (vii) describe the labour market block. Equation (v) defines the seasonally-adjusted unemployment rate as the sum of its trend $\left(\overline{\mathrm{u}}_{\mathrm{t}}\right)$ and cyclical $\left(\tilde{\mathrm{u}}_{\mathrm{t}}\right)$ components. Equation (vi) defines the dynamics of trend unemployment (NAIRU) as a random walk. A dynamic Okun's Law at cyclical frequency is described in equation (vi), linking the unemployment gap to the output gap.

The cyclical component of foreign demand follows a first-order autoregressive process.

\subsection{Estimation}

Equations (i) to (viii) are estimated as a system using Bayesian inference on quarterly data from 2000Q1 to 2016Q2 using real GDP, the unemployment rate and the cyclical component of foreign demand as observables. The application of Bayesian methods is especially important for an economy like Malta due to its relatively short sample.

Table 4 reports prior mean and distribution as well as the posterior mean and the 68 percent confidence intervals of the posterior distribution computed with the Metropolis Hastings algorithm. The results are based on two chains of 100,000 draws each, after discarding the first $20 \%$ of the draws. The average acceptance rate is $31.5 \%$ for both chains. The choice of priors relied heavily on similar studies in the literature, in particular Micallef (2016). In terms of the prior distributions, the beta distribution was used for parameters constrained on the unit interval $\left(\tau, \theta_{1}, \alpha_{1}\right.$ and $\left.\rho\right)$, the gamma distribution was chosen for parameters in $\operatorname{R}+\left(\theta_{2}\right.$ and $\left.\alpha_{2}\right)$, the normal distribution for the steady-state growth (g) while the inverse gamma distribution was chosen for the standard deviation of the shocks. Given its empirical counterpart, the share of labour in GDP $(\vartheta)$ was calibrated ex-ante at 0.58 , equivalent to the share of compensation of employees in gross value added, adjusted for the share of self-employed. 
Table 4. Estimation Results

\begin{tabular}{lcccccc}
\hline Parameter & Prior distribution & Prior Mean & $\begin{array}{c}\text { Prior } \\
\text { standard } \\
\text { deviation }\end{array}$ & $\begin{array}{c}\text { Posterior } \\
\text { Mean }\end{array}$ & 68\% HPD interval \\
\hline$\tau$ & Beta & 0.10 & 0.05 & 0.105 & 0.044 & 0.134 \\
$\theta 1$ & Beta & 0.70 & 0.10 & 0.531 & 0.428 & 0.639 \\
$\theta 2$ & Gamma & 0.35 & 0.10 & 0.166 & 0.127 & 0.195 \\
$\alpha 1$ & Beta & 0.70 & 0.10 & 0.629 & 0.536 & 0.714 \\
$\alpha 2$ & Gamma & 0.15 & 0.10 & 0.119 & 0.081 & 0.141 \\
$\rho$ & Beta & 0.70 & 0.10 & 0.819 & 0.778 & 0.866 \\
$\mathrm{~g}$ & Normal & 2.80 & 0.50 & 2.771 & 2.431 & 3.155 \\
Standard de viation of shocks & & & & & \\
$\mathrm{E}^{\widetilde{y}}$ & Inverse gamma & 0.75 & inf & 0.555 & 0.369 & 0.734 \\
$\varepsilon^{\bar{y}}$ & Inverse gamma & 0.35 & inf & 0.409 & 0.129 & 0.521 \\
$\varepsilon^{\mathbf{G}}$ & Inverse gamma & 0.65 & inf & 0.468 & 0.228 & 0.545 \\
$\varepsilon^{\widetilde{\mathbf{u}}}$ & Inverse gamma & 0.50 & inf & 0.234 & 0.195 & 0.271 \\
$\varepsilon^{\overline{\mathbf{u}}}$ & Inverse gamma & 0.10 & 0.05 & 0.121 & 0.079 & 0.141 \\
$\varepsilon^{\overline{\text { yfor }}}$ & Inverse gamma & 0.75 & inf & 1.824 & 1.639 & 1.948 \\
\hline
\end{tabular}

Among the main results, Okun's coefficient is estimated at 0.12 , slightly lower than the prior mean, but broadly in line with the empirical estimates presented above. The lagged impact of the cyclical component of unemployment is somewhat stronger than its counterpart in the output gap equation, implying a moderately more persistent unemployment gap compared to the output gap. Finally, the steady state growth rate is estimated at $2.8 \%$, broadly in line with the prior, but higher than the $2.6 \%$ reported in Micallef (2016).

Chart 3 plots the trend components of unemployment and output, along with the actual unemployment rate and real GDP growth. Both exhibits show clear patterns in the trends, with a downward decline in NAIRU and an increase in the economy's potential growth rate after the crisis. The decline in NAIRU broadly mirrors the results from the rolling regression estimates presented in section 3.1 above.

\section{Unemployment and NAIRU}

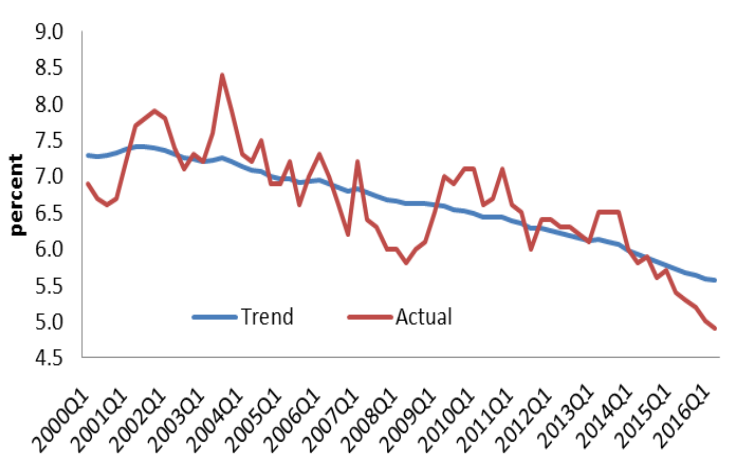

Actual and trend GDP growth

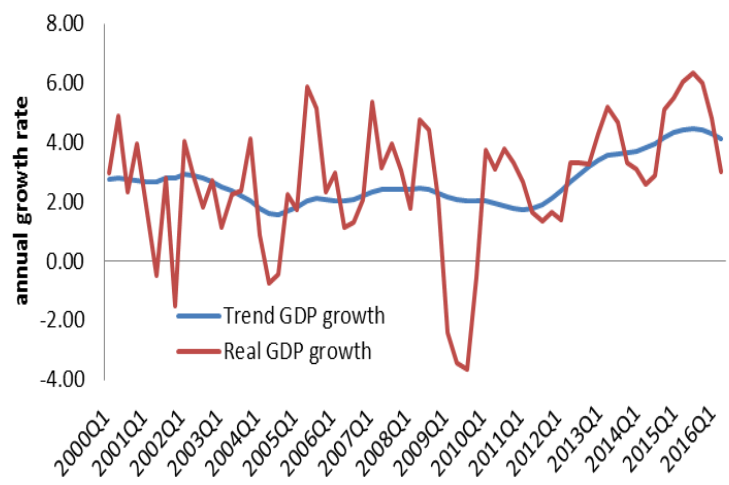

Chart 3. Development in Trend Components

In the early 2000s, NAIRU was relatively high, standing above $7 \%$. This period was characterised by sluggish economic growth, owing both to adverse demand conditions that hit the economy and the introduction of foreign competition in certain industries in the run-up to EU membership. The latter, however, proved the catalyst for the diversification of the economy from traditional industries to higher value added ones, mostly in the services sector but also in manufacturing. According to the model, the recession of 2009 had no impact on NAIRU as, after a temporary increase in the unemployment rate, the latter resumed its downward trend already by 2010, reaching historical lows by the first half of 2016. (Note 3) This labour market performance was due to a number of factors, including the timely and targeted intervention of the authorities to assist companies in the distress during the recession, mostly in the manufacturing and tourism sectors, the diversification of the economy to sectors which proved resilient to the recession and the absence of 
major shocks in the financial sector (Micallef, 2013). The decline in NAIRU was accompanied by high employment growth and an increase in the participation rate, mostly of females, all of which contributed positively to the increase in Malta's potential growth rate.

The decline in NAIRU was underpinned by numerous initiatives in recent years to strengthen the employability prospects of certain target groups, including through the provision of training and on-the-job experiences. A number of training scheme were launched that were targeted for persons with a low level of education or above 45 years of age. A national apprentice scheme was launched in order to strengthen the link between academia and industry requirements. The latter was intended to complement the rise in vocational training through the establishment of the Malta College of Arts, Science and Technology (MCAST) in the early 2000s.

A number of initiatives were also taken to motivate more people to join and stay longer in the labour market rather than rely on unemployment benefits. For instance, to further facilitate their integration into the labour market, long-term unemployed individuals are awarded a percentage of social benefits for three years once employed. In addition, measures were also introduced to curtail abuse of the unemployment register. The latter initiatives contributed to curb undeclared work and encourage people to enter the formal economy.

Chart 4 depicts the scatterplots of the output-unemployment relationship at the cyclical and trend frequency from the semi-structural filter. The results are quite stark.

\section{Okun's Law at cyclical frequency}

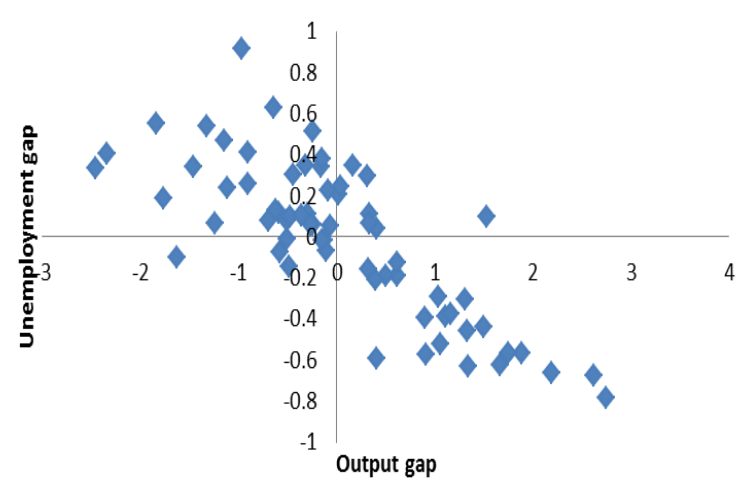

\section{Okun's Law at trend frequency}

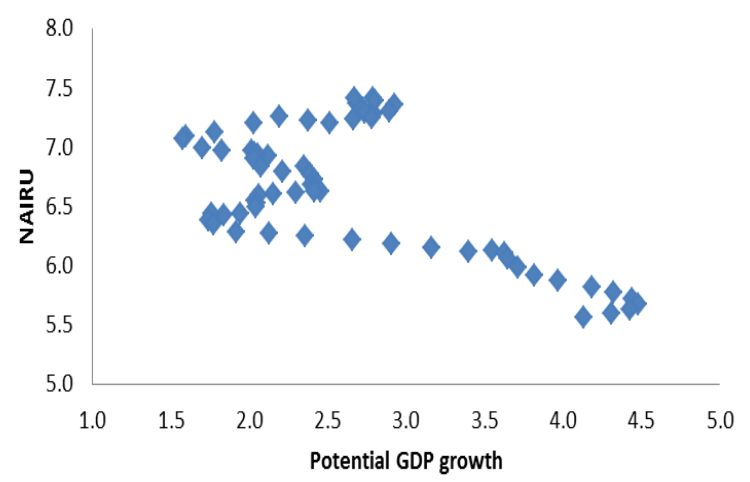

Chart 4. Output-Unemployment Relationship at Cyclical and Trend Frequencies

At cyclical frequency, Okun's Law is quite robust and does not seem to be time-variant, not even by the impact of the Great Recession of 2009. This finding is in line with Lafourcade et al (2016), who also report that Okun's Law appears to be a robust feature of macro data across time, countries and different trend-cycle identification schemes. For Malta, the correlation coefficient between the two gaps stand at -0.79 .

On the contrary, the output-unemployment dynamics at lower frequency, interpreted as trend developments, could be the source of the instability in Malta Okun's Law over time. For instance, in the immediate aftermath of the Great Recession, potential output slowed down compared to its pre-crisis peak whereas NAIRU maintained its downward trends. A similar situation occurred in the early 2000 s, with both trends moving in the same direction.

The trend-cycle decomposition shed important light on the output-unemployment relationship at various frequencies. Instability in one dimension could provide an explanation of the breakdown in the aggregate Okun's relationship that is commonly reported in the literature, especially after the crisis. More importantly, the identification of a stable relationship at cyclical frequency, which could perhaps be clouded in the aggregate data due to the instability at lower frequency, comes with important policy implications, which we'll focus on in the concluding section.

\section{Conclusion}

This study presents a number of observations on the linkages between economic activity and the labour market in Malta. The relationship between output and unemployment in Malta is relatively weak compared with other European countries. Among the demand components, unemployment is mostly sensitive to private consumption and exports. The relationship is also asymmetric, with the response of unemployment to output tending to be more pronounced during recessions. Stability tests suggest that Okun's relationship is not stable, although the link has become more pronounced in recent years, while NAIRU has been on a downward trend. Estimates from an unobserved components model suggests that Okun's Law is quite robust at cyclical frequency, with potential time-variation in the relationship being ascribed to the trend components. 
The asymmetric relationship between output and unemployment, as well as the tight relationship between the two at business cycle frequency, have important policy implications. They strengthen the call for prudent fiscal policy over the economic cycle to create fiscal space in good times, thereby allowing room for manoeuvre in a downturn. Furthermore, one implication of asymmetry is that job creation after a recession may be insufficient to absorb the newly unemployed. This calls for appropriate training to meet the changing skill requirements of the new industries, thereby facilitating the re-integration of the unemployed in the labour market.

The downward trend in Malta's NAIRU, especially after the crisis, is in stark contrast to the experience of most other EU countries. However, remaining bottlenecks in the domestic labour market should still be addressed. Despite considerable improvements in recent years, Malta ranks at the bottom end of EU rankings in terms of education attainment, while a shortage of skilled labour, in part due to a mismatch between the demand and supply of skills, are constantly identified by firms as one of their main concerns. Measures and initiatives targeted at these two areas, in conjunction with others intended to strengthen the links between academia and industry, can help in improving the flexibility of the domestic labour market and enhance the efficiency of the matching process between job seekers and vacancies.

\section{References}

Apap, W., \& Gravino, D. (2014). Okun's Law in Malta: lessons learnt from a sectoral perspective. Working Paper WP/01/2014, Economic Policy Department, Ministry for Finance, Malta. Retrieved from: https://mfin.gov.mt/en/epd/Documents/Working_Papers/Working\%20Paper\%20Okun's\%20Law\%20full.pdf

Ball, L., Leigh, D., \& Loungani, P. (2012). Okun's Law: Fit at 50?. NBER Working Paper No. 18668. Retrieved from: http://www.nber.org/papers/w18668

Benes, J., Clinton, K., Garcai-Saltos, R., Johnson, M., Laxton, D., Manchev, P., \& Matheson, T. (2010). Estimating potential output with a multivariate filter. IMF Working Paper WP/10/285. Retrieved from: https://www.imf.org/external/pubs/ft/wp/2010/wp10285.pdf

Blanchard, O., \& Summers, L. (1986). Hysteresis and European Unemployment. In NBER Macroeconomics Annual pp. 15-77. Edited by Fischer, S. September, MIT Press.

Blanchard, O., Cerutti, E., \& Summers, L. (2015). Inflation and activity - Two explorations and their monetary policy implications, IMF Working Paper WP/15/230. Retrieved https://www.imf.org/external/pubs/ft/wp/2015/wp15230.pdf

Carabenciov, I., Ermolaev, I., Freedman, C., Juillard, M., Kamenik, O., Korshunov, D., \& Laxton, D. (2008). A Small Quarterly Projection Model of the US Economy. IMF Working Paper WP/08/278. Retrieved from: https://www.imf.org/external/pubs/ft/wp/2008/wp08278.pdf

Cazes, S., \& Verick, S. (2011). What has happened to Okun's law in the US and Europe? Insights from the great Recession and longer time trends. Key Lessons from the Crisis and the Way Forward, Research Conference, ILO.

Central Bank of Malta (2012). Wage Dynamics Report: Malta. https://www.centralbankmalta.org/updates/Downloads/pdfs/wage_dynamics_report.pdf

D’Auria, F., Denis, C., Havik, K., McMorrow, K., Planas, C., Raciborski, R.., Roger, W., \& Rossi, A. (2010). The production function methodology for calculating potential growth rates and output gaps. European Commission Economic Papers No. 420. Retrieved from: http://ec.europa.eu/economy_finance/publications/economic_paper/2014/pdf/ecp535_en.pdf

ECB (2011). Back to Okun's Law? Recent developments in euro area output and unemployment, ECB Monthly Bulletin, ECB June 2011.

ECB (2012a). Recent developments in the Okun relationship in the euro area, ECB Monthly Bulletin, ECB July 2012.

ECB (2012b). Euro area labour markets and the crisis, Occasional Paper No. 138, ECB. Retrieved from: https://www.ecb.europa.eu/pub/pdf/other/euroarealabourmarketsandthecrisis201210en.pdf

ECB (2015). Comparisons and contrasts of the impact of the crisis on euro area labour markets, ECB Occasional Paper No. 159. Retrieved from: https://www.ecb.europa.eu/pub/pdf/scpops/ecbop159.en.pdf

Gordon, R. (1997). The time-varying NAIRU and its implications for economic policy. Journal of European Perspectives, Volume 11. Retrieved from: http://www.jstor.org/stable/2138249

Grech, A. G. (2013). Adapting the Hodrick-Prescott filter for very small open economies. International Journal of Economics and Finance, 5(8). http://dx.doi.org/10.5539/ijef.v5n8p39

Grech, A. G. (2015). The diversification of the Maltese economy. Central Bank of Malta Policy Note, September 2015. 
Grech, A. G., \& Micallef, B. (2015). Assessing the supply side of the Maltese economy using a production function approach. Xjenza, 3(1), 57-63. http://dx.doi.org/10.7423/XJENZA.2015.1.08

Grech, O. \& Micallef, B. (2014). A structural macro-econometric model of the Maltese economy. Central Bank of Malta Working Paper version 2, November 2014. Retrieved from: https://www.centralbankmalta.org/macro-econometric-model

IMF (2012). Unemployment dynamics during recessions and recoveries: Okun's law and beyond. World Economic Outlook, 69-108.

Knotek, E. (2007). How useful is Okun's law? Economic Review, 4, 73-103, Federal Reserve Bank of Kansas City. Retrieved from: https://www.kansascityfed.org/publicat/econrev/pdf/4q07knotek.pdf

Lafourcade, P. et al. (2016). Labour market modelling in the light of the financial crisis, ECB Occasional Paper No. 175. https://www.ecb.europa.eu/pub/pdf/scpops/ecbop175.en.pdf?b0080484af75491e40010fc129b53967

Micallef, B. (2013). Labour market resilience in Malta. Central Bank of Malta Quarterly Review 2013(1).

Micallef, B. (2016). A multivariate filter to estimate potential output and NAIRU for the Maltese economy. International Journal of Economics and Finance, 8, 5. http://dx.doi.org/10.5539/ijef.v8n5p13

Okun, A. M. (1962). Potential GNP: Its Measurement and Significance. American Statistical Association. Proceedings of the Business and Economic Statistics Section, 98-104.

\section{Notes}

Note 1. This category includes information \& communication, finance \& insurance, real estate activities, professional, scientific \& technical sectors and the recreation sector.

Note 2. Identities (i) and (v) are augmented with measurement errors to account for the high degree of volatility that characterise the time series of very small open economies (Grech, 2013). As in Micallef (2016), the variance of the measurement errors was calibrated to correspond to around $15 \%$ of the variance in GDP growth and the change in the unemployment rate.

Note 3. This result is robust to different specifications. For instance, Micallef (2016) includes also the output gap in NAIRU to capture partial hysteresis effects. The main conclusion of a downward trend in NAIRU remains unchanged.

\section{Copyrights}

Copyright for this article is retained by the author(s), with first publication rights granted to the journal.

This is an open-access article distributed under the terms and conditions of the Creative Commons Attribution license which permits unrestricted use, distribution, and reproduction in any medium, provided the original work is properly cited. 